\title{
Selection of commercially available scooters by new MCDM method
}

\author{
Tapas Kumar Biswas ${ }^{a^{*}}$ and Pritha Saha ${ }^{\mathrm{b}}$
}

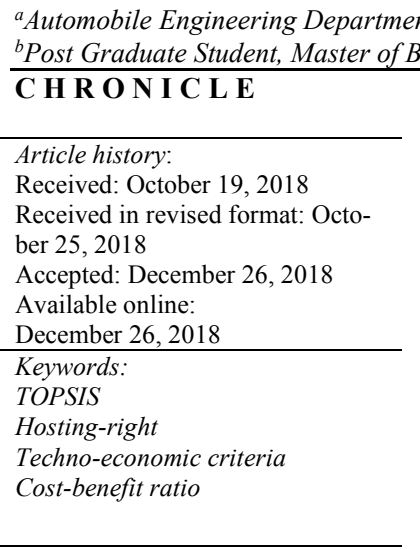
\begin{abstract}
A B S T R A C T
This paper presents the application of the new method in the process of making the decisions on the scooters selection. The Fuzzy AHP method was used to obtain the weight coefficients of criteria, on the basis of which the alternatives were evaluated. The selection of criteria for evaluating scooters was based on an analysis of available manufacturer website. The evaluation and selection of scooters was carried out using a new multi-criteria decision making (MCDM) method. The present study tries to identify the attributes like kerb weight, mileage, top speed, fuel tank capacity and price playing prominent role in the buying behavior of the working women while purchasing scooters. Fuzzy-AHP method has been used to obtain the relative weights of the criteria, on the basis of which the alternatives are evaluated using new MCDM. The TOPSIS and MABAC methods were tested under the same conditions. The stability of the result obtained by this method is established through a sensitivity analysis.
\end{abstract}

(C) 2019 by the authors; licensee Growing Science, Canada.

\section{Introduction}

Two wheelers such as scooters, motor bikes and mopeds are considered as a popular and dominant transportation facilities in different parts of the world, especially in Asia (Hsu et al., 2003; Haworth, N., 2012). The common disadvantages of this mode of transportation are the exposure to extremes of weather, the machines instability, limited number of passengers, limited capacity for transportations of goods, limited range, lack of security from thieves, and its susceptibility during accidents (Rose et al., 2012) but it provides an affordable form of personal transportation, which requires fewer number of resources (fuel, materials and space) for many people in developing countries. The motorcycle utilizes only $15-20 \%$ of the space per person required by a car. It also consumes less energy in production and operation, as well as emitting less $\mathrm{CO}_{2}$ (Hsu et al., 2003; Rose et al., 2012). The reduced space required for parking, and slowing the demand for additional roads, can reduce urban sprawling. Moreover, the scooters have a lower purchase cost with a car costing around 10 times more than a scooters. Therefore scooters are a more economical mean of transportation.

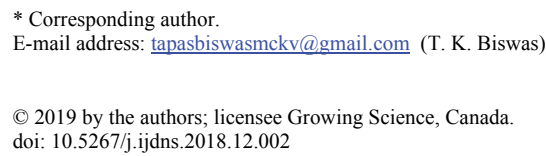


In recent years, Indian automobile industry has seen a dynamic growth especially in Two-wheeler segment. India is the second largest producer of two-wheelers in the world. The younger generation of India is interested in two-wheelers and hence prefers two-wheeler over four-wheeler. One of the major segments in the two-wheeler section is the scooter with the latest models, new designs, new features, cuttingedge technology. The two wheeler market in India has been growing at a rapid rate and is fueled by increasing purchasing power in rural and urban area. Market analysts believe that demand for scooters is beginning to penetrate into smaller towns and rural pockets. While factors such as fuel efficiency continue to dominate in the smaller towns, low maintenance costs, top speed, low kerb weight and the ease of riding (automatic scooters) are gaining awareness in the rural markets. There are list of two wheelers available the Indian market like Hero, TVS, Yamaha and Honda etc. are launching the gear less and low weight scooters.

Vehicle selection is a multi-attribute decision-making (MADM) process. Researchers have used various methods for the decision-making process when selecting the most suitable potential vehicles. For example Biswas and Das (2018a) presented a decision support system for hybrid vehicle selection by entropyMABAC method. Biswas and Das (2018b) MCDM process for electric vehicle selection based on fuzzy AHP and MABAC method. Previous findings have shown that the applications of the SAW, MOORA, COPRAS, TOPSIS, MABAC and VIKOR algorithms are widely used in the decision-making process. This paper presents the application of a new method in the process of selecting scooters. After this, the results obtained are compared with the results from the MABAC (Pamucar \& Cirovic, 2015) and TOPSIS (Dağdeviren et al., 2009) methods. Through a sensitivity analysis of the given methods, their objective evaluation is carried out. The fuzzy AHP method is used in the process of evaluating the criteria and determining the weight coefficients.

The paper is organized as follows: after the introductory considerations and literature analysis, Section 2 presents the research plan with mathematical formulation of the new MCDM method and the basic steps of the new method. Section 3 contains an application of the fuzzy AHP- new MCDM model. A sensitivity analysis for the new method is presented in Section 4. After discussion in section 5 the final section (Section 6) presents the concluding remarks and directions for future research. The aim of this paper to choose the best alternative scooter which can reduce space for parking, kerb weight and give the better mileage to the future generation of the woman. Here seven scooters have been chosen as alternatives for selection and ranking under passenger car category. These alternatives are coded as V1 to V7 respectively in the remaining part of this paper.

\section{Research plan}

\subsection{Selection of evaluation criteria}

In multi-criteria environment, performance of alternatives in absolute sense is very difficult to measure. There are lot of criteria/factors/attributes exist that affect the performance. All seven scooters which are chosen for comparison are similar enough to be compared.

\subsection{Importance of criteria}

Out of five criteria, fuel tank capacity (C2), mileage (C3) and top speed (C4) are beneficial criteria, i.e. higher the better type. Remaining two are non-beneficial criteria. In this present research fuzzy AHP method has been used to determine the relative importance of the criteria.

\subsubsection{Description of criteria}

Kerb weight (C1): Kerb weight is the weight of all the standard equipment fitted on the vehicle, consumable items such as engine oil, coolant, brake oil etc. and a completely filled fuel tank is taken into account. 
Most of the two wheeler manufacturers are taking interest to make less weight bikes by targeting female buyers.

Fuel tank capacity (C2): Another important criterion is fuel tank capacity, maximum fuel tank capacity means maximum distance can cover by vehicle. It is represents by liter.

Mileage (C3): This criterion is expressed as kilometer per liter (KMPL). It represents the number of kilometers the vehicle can go using a quantity of fuel.

Top speed (C4): It is the maximum speed at which the vehicle can run. It is expressed in the kilometer per hour.

Price (C5): It is the selling price of vehicle in India. It is important criteria from customers' perspective.

\subsection{The Proposed model}

Multiple criteria decision making can be employed to select and prioritize the alternatives in a set. Various multiple criteria analysis tools like-AHP (Analytical Hierarchy Process) (Saaty, 1980), DEA (Data Envelopment Analysis) (Charnes et al., 1978), ELECTRE (ELimination Et Choix Traduisant la REalité) (Roy, 1968), PROMETHEE (Preference Ranking Organization Method for Enrichment Evaluations) (Brans, 1982) are available for performance evaluation and ranking of alternatives. In this paper we use fuzzy AHP to find out the weights of the evaluation criteria and the new MCDM method for performance evaluation. The step-wise method for computing relative weights of evaluation criteria has been adopted from the work of Das et al. (2012). The proposed performance model starts with the definition of decision matrix which has in general four components, such as: (i) alternatives (ii) criteria or attributes (iii) subjective weights or relative importance of each criteria and (iv) measure of performance of alternatives with respect to the criteria.

\subsubsection{New MCDM method}

The general steps of the new MCDM method are as follows.

Step 1. A decision matrix is formed and expressed as follows.

$$
\begin{aligned}
& \begin{array}{lllllll}
F_{1} & F_{2} & . . & F_{j} & . . & F_{n}
\end{array}
\end{aligned}
$$

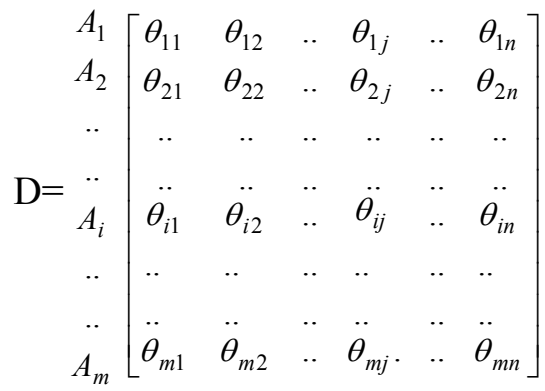

where $A_{i}$ represents the alternatives, $i=1,2, \ldots, m ; F_{j}$ represents $j$ th attribute or criterion, $j=1,2, \ldots$, $n$, related to $i$ th alternative; and $\theta_{i j}$ indicates the performance rating of each alternative $A_{i}$ with respect to each criterion $F_{j}$.

The procedures of new method are follows:

Step 1.Formation of the initial decision matrix $X=\left[\mathrm{x}_{\mathrm{ij}}\right]_{\mathrm{mxn}}$.

Step 2.Normalize the decision matrix as $\mathrm{N}=\left[\mathrm{r}_{\mathrm{ij}}\right]_{\mathrm{mxn}}$. 
(a) This method first converts the various criteria dimensions into non-dimensional criteria. For Benefit and non-beneficial type criteriar ${ }_{i j}$ is calculated as follows,

$$
r_{i j}=\frac{x_{i j}-x_{i}^{-}}{x_{i}^{+}-x_{i}^{-}}
$$

(b) For Non beneficial type criteria

$$
r_{i j}=\frac{x_{i j}-x_{i}^{+}}{x_{i}^{-}-x_{i}^{+}} .
$$

Here, $x_{i j}, x_{i}{ }^{+}$and $x_{i}{ }^{-}$are the elements from the initial decision matrix $(\mathrm{X})$, where $x_{i}{ }^{+}=\max \left(x_{1}, x_{2}, \ldots, x_{m}\right)$ and $x_{i}^{-}=\min \left(x_{1}, x_{2}, \ldots, x_{m}\right)$.

Step 3. When normalized value of all these criteria lie in the interval of $(>0.80,1.00]$, then take scale factor, $g=5$. if normalized value of one of these criteria lies in the interval of $(>0.60,0.80)$, then $g=4$, when normalized value of all criteria lie in the interval of $(>0.40,0.60)$ then scale factor $g=3,(>0.20,40)$ then scale factor is 2 and $(>0,0.20)$ then $\mathrm{g}=1$. Then forms scaled normalize decision matrix $(\mathrm{V})$.

Step 4. The elements of the weighted normalized matrix (V) are calculated on the basis of the expression.

$$
q_{i j}=w_{i} \cdot v_{i j}
$$

Step 5. Compute overall score of the alternatives using the following equation.

$$
S_{i}=\sum_{j=1}^{n} q_{i j}
$$

Rank the alternatives based on decending value of $S_{i}$.

\section{Application of the proposed model}

The proposed fuzzy AHP and new MCDM method for selection of vehicle consists of two basic stages: (i) determination of relative importance of evaluation criteria using FAHP and (ii) ranking of alternatives using new method. After identification of evaluation criteria with the help of experts in the domain, fuzzy scale with linguistic values as proposed by Chang (1996) are used to find relative weights of criteria.

\subsection{Weights of criteria}

Considering the feedback of the experts from various fields, pair-wise comparison matrix (shown in Table 2) of 5 criteria has been formed to get their relative weight over other.

\section{Table 1}

Pairwise comparison matrix

\begin{tabular}{llllll}
\hline Criteria & \multicolumn{5}{l}{} \\
\hline Mileage & $(1,1,1)$ & $(1.5,2,2.5)$ & $(0.67,1,1.5)$ & $(2.5,3,3.5)$ & $(0.67,1,1.5)$ \\
Top speed & $(0.4,0.5,0.67)$ & $(1,1,1)$ & $(0.67,1,1.5)$ & $(0.67,1,1.5)$ & $(1.5,2,2.5)$ \\
Kerb weight & $(0.67,1,1.5)$ & $(0.67,1,1.5)$ & $(1,1,1)$ & $(0.67,1,1.5)$ & $(2.5,3,3.5)$ \\
Fuel tank capacity & $(0.29,0.33,0.4)$ & $(0.67,1,1.5)$ & $(0.67,1,1.5)$ & $(1,1,1)$ & $(1.5,2,2.5)$ \\
Price & $(0.4,1,1.5)$ & $(0.4,0.5,0.67)$ & $(0.29,0.33,0.4)$ & $(0.4,0.5,0.67)$ & $(1,1,1)$ \\
\hline
\end{tabular}

Now, following the step-wise method of fuzzy AHP as elaborated in Das et al. (2012) and by considering the data presented in Table 3, the weight vector is determined as

$$
\mathrm{W}=(0.316,0.278,0.201,0.186,0.019)^{\mathrm{T}}
$$


Therefore, we determine the final weights (shown in Table 3) of 5 criteria of mileage, top speed, kerb weight, fuel tank capacity and price as $0.316,0.278,0.201,0.186$ and 0.019 respectively.

Table 2

Criteria Weights

\begin{tabular}{ccccc}
\hline Mileage & Top speed & Kerb weight & Fuel tank capacity & Price \\
\hline 0.316 & 0.278 & 0.201 & 0.186 & 0.019 \\
\hline
\end{tabular}

\subsection{Data and computation}

In this section, new MCDM methodology will be applied to evaluate seven alternatives of the scooters in India. Here seven alternatives (V1), (V2), (V3), (V4), (V5), (V6) and (V7) and five criteria are considered. The data for five criteria for seven alternatives was presented in Table 3 and the all data has taken from manufacturer website. The normalized data according to Eq. (2) and Eq. (3) has been presented in Table 4. Table 6 shows the weighted normalized data for each alternative is calculated using Eq. (4). The result of the computation rank is also shown in Table 7.

Table 3

The information of the case study

\begin{tabular}{|c|c|c|c|c|c|}
\hline Alternatives & $\begin{array}{l}\text { Combined fuel econ- } \\
\text { omy }(\mathrm{km} / \mathrm{l})\end{array}$ & $\begin{array}{l}\text { Battery Range(kilo- } \\
\text { meter) }\end{array}$ & $\begin{array}{l}\text { Top speed on a flat } \\
\operatorname{road}(\mathrm{KMPH})\end{array}$ & $\begin{array}{l}\text { Accelerating Time } \\
(\mathrm{Sec})\end{array}$ & $\begin{array}{c}\text { Base Model } \\
\text { Price(Rs.) }\end{array}$ \\
\hline $\mathrm{V} 1$ & 108 & 5.3 & 54 & 84 & 59563 \\
\hline $\mathrm{V} 2$ & 103 & 5 & 40 & 84 & 53451 \\
\hline V3 & 105 & 5.6 & 64 & 78 & 53000 \\
\hline V4 & 101 & 5 & 45 & 77 & 48019 \\
\hline V5 & 102 & 5 & 62 & 85 & 49966 \\
\hline V6 & 110 & 6 & 50 & 100 & 69,714 \\
\hline V7 & 103 & 5.3 & 45 & 83 & 49849 \\
\hline
\end{tabular}

\section{Table 4}

Normalized matrix

\begin{tabular}{|c|c|c|c|c|c|}
\hline \multirow[t]{2}{*}{ Alternatives } & Kerb Weight(Kg) & $\begin{array}{c}\text { Fuel tank } \\
\text { capacity(Litres) }\end{array}$ & Mileage $(\mathrm{Km} /$ litre $)$ & Top speed(Km/hour) & Price(Rs.) \\
\hline & $\mathrm{C} 1$ & $\mathrm{C} 2$ & $\mathrm{C} 3$ & $\mathrm{C} 4$ & $\mathrm{C} 5$ \\
\hline V1 & 0.777777778 & 0.3 & 0.583333333 & 0.695652174 & 0.467895829 \\
\hline $\mathrm{V} 2$ & 0.222222222 & 0 & 0 & 0.695652174 & 0.749619728 \\
\hline V3 & 0.444444444 & 0.6 & 1 & 0.956521739 & 0.770407928 \\
\hline V4 & 0 & 0 & 0.208333333 & 1 & 1 \\
\hline V5 & 0.111111111 & 0 & 0.916666667 & 0.652173913 & 0.910255819 \\
\hline V6 & 1 & 1 & 0.416666667 & 0 & 0 \\
\hline V7 & 0.222222222 & 0.3 & 0.208333333 & 0.739130435 & 0.915648767 \\
\hline
\end{tabular}

Table 5

Scaled Normalized decision matrix

\begin{tabular}{cccccc}
\hline \multicolumn{2}{c}{ Criteria } & & & & \\
\hline \multirow{2}{*}{ Alternatives } & $\begin{array}{c}\text { Kerb } \\
\text { Weight(Kg) }\end{array}$ & $\begin{array}{c}\text { Fuel tank capacity } \\
\text { (Litres) }\end{array}$ & Mileage(Km/litre) & Top speed(Km/hour) & Price(Rs.) \\
\hline V1 & C1 & C2 & C3 & C4 & C5 \\
\hline V2 & 4 & 2 & 3 & 4 & 3 \\
V3 & 2 & 1 & 1 & 5 & 4 \\
V4 & 3 & 3 & 5 & 5 & 5 \\
V5 & 1 & 1 & 5 & 4 & 5 \\
V6 & 1 & 1 & 3 & 1 & 5 \\
V7 & 5 & 2 & 2 & 4 & 5 \\
\hline
\end{tabular}


Table 6

Weighted normalized decision matrix

\begin{tabular}{|c|c|c|c|c|c|}
\hline & Criteria & & & & \\
\hline \multirow[t]{2}{*}{ Alternatives } & Kerb Weight $(\mathrm{Kg})$ & $\begin{array}{l}\text { Fuel tank capac- } \\
\text { ity(Litres) }\end{array}$ & Mileage $(\mathrm{Km} / \mathrm{litre})$ & Top speed(Km/hour) & Price(Rs.) \\
\hline & $\mathrm{C} 1$ & $\mathrm{C} 2$ & $\mathrm{C} 3$ & $\mathrm{C} 4$ & $\mathrm{C} 5$ \\
\hline V1 & 1.264 & 0.556 & 0.603 & 0.744 & 0.057 \\
\hline V2 & 0.632 & 0.278 & 0.201 & 0.744 & 0.076 \\
\hline V3 & 0.948 & 0.834 & 1.005 & 0.930 & 0.076 \\
\hline V4 & 0.316 & 0.278 & 0.603 & 0.930 & 0.095 \\
\hline V5 & 0.316 & 0.278 & 1.005 & 0.744 & 0.095 \\
\hline V6 & 1.580 & 1.390 & 0.603 & 0.186 & 0.019 \\
\hline V7 & 0.632 & 0.556 & 0.402 & 0.744 & 0.095 \\
\hline
\end{tabular}

Table 7

Rank of the alternative using proposed method

\begin{tabular}{cccc}
\hline Alternatives & $\mathrm{Si}$ & Rank \\
\hline V1 & 3.224 & 3 & 7 \\
V2 & 1.931 & 1 & 6 \\
V3 & 3.793 & 4 & \\
V4 & 2.222 & 2 & 5 \\
V5 & 2.438 & 3.778 & 5 \\
V6 & 2.429 & \\
V7
\end{tabular}

\section{Sensitivity Analysis}

A sensitivity analysis of the MABAC method was carried out in two phases. The first phase of FAHPnew MCDM method has been carried out to explore the stability of the solution to a change in the criteria weight. The importance of evaluation criteria has been determined with the help of expert's opinion in fuzzy environment. There are five criteria (C1-C5), the possible number of interchanges become ten $\left(\mathrm{C}_{2}\right)$. Thus ten sets of priority rankings of two wheelers are available and the same have been shown in the sensitivity plot in Fig. 1, which prioritizes candidate-scooters when comparing the same with the associated candidate alternatives by interchanging the weights of a pair of criteria.

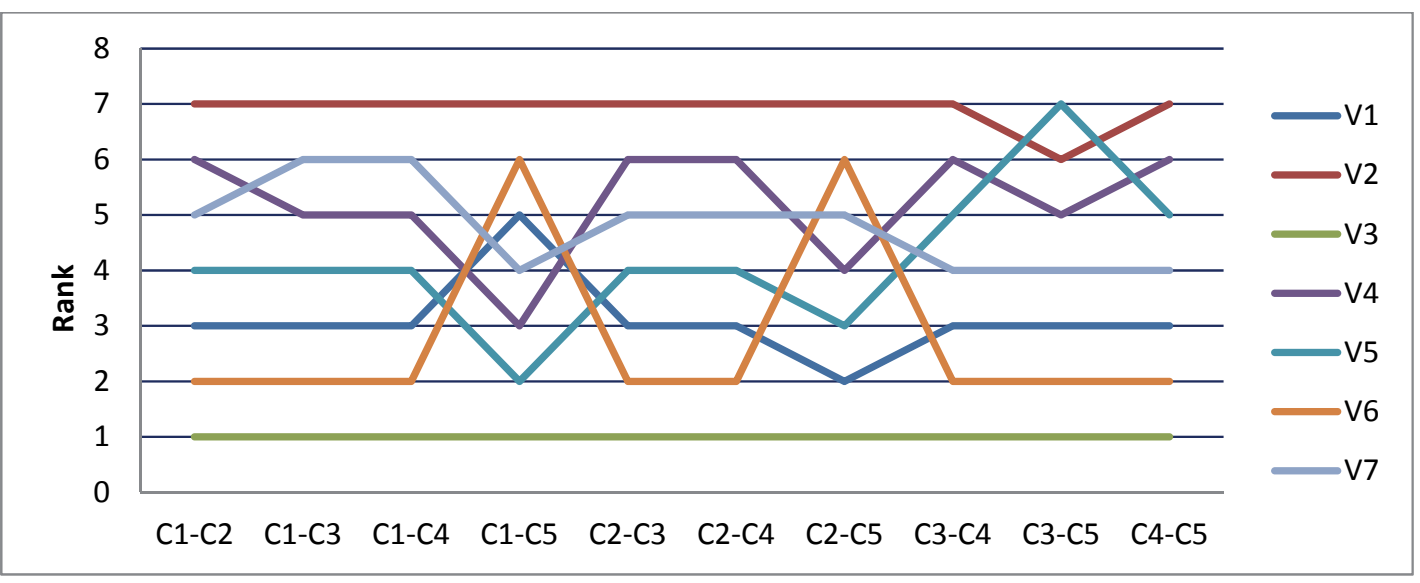

Fig. 1. Sensitivity plot

It may be noted from the sensitivity plot that the ranking of the alternatives changes a little with the interchanging of criteria weight. However all the cases V3 outperforms over other. The figure also shows that the performance of V2 andV4 needs improvement. This analysis provides a glimpse of changes in relative ranking with interchanging of criteria weights. It is clear from the sensitivity plot that, in general, the rankings of the two wheelers do not vary greatly even often interchanging the criteria weights. This clearly indicates ranking of the scooters obtained by the proposed FAHP-new MCDM method is highly justified. Secondly, in order to show the applicability and potential of the proposed method, the same MCDM problems following published methods like TOPSIS and MABAC have been considered. We 
have solved the same scooter (two wheeler) selection problem using fuzzy AHP- TOPSIS method and fuzzy AHP- MABAC method and observed the ranking of the alternatives as 3-7-1-5-2-4-6 and 3-7-1-64-2-5 and observed the ranking of the alternatives which reveals that V3 is the best choice and V2 is worst. The graphical view of ranking of alternative robots using fuzzy AHP-TOPSIS, fuzzy AHPMABAC and proposed methods are shown in Fig. 2.

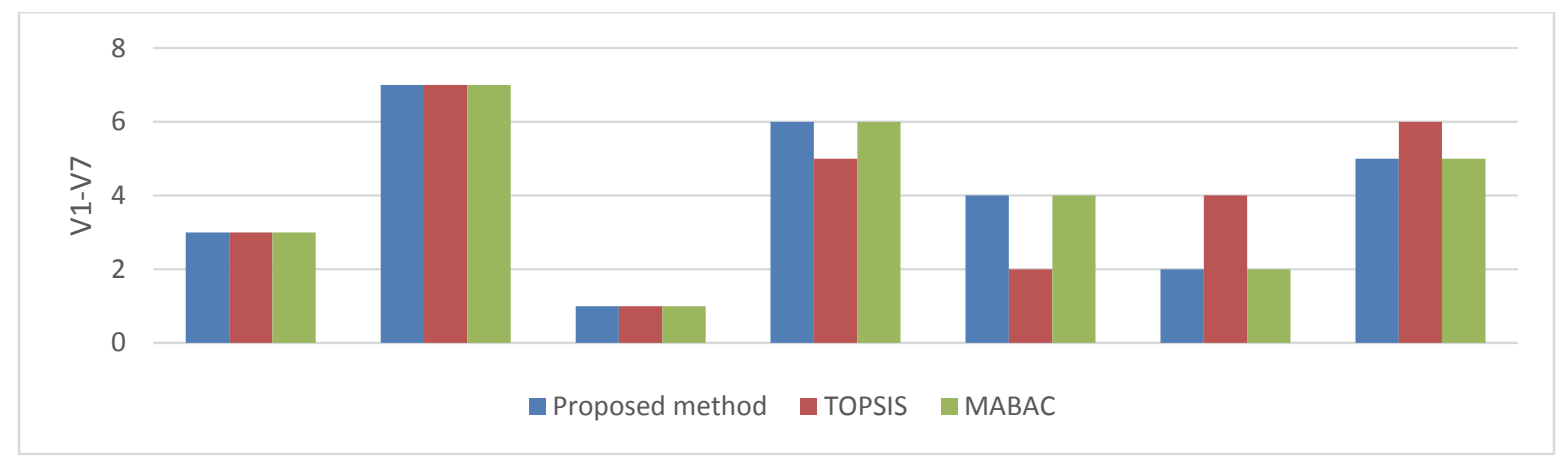

Fig. 2. Ranking of scooters in various methods

\section{Discussion}

It is perceived that in evaluation to other MCDM methods, like ELECTRE, VIKOR, PROMETHEE, DEA, etc., the proposed method i.e., new MCDM is very simple to understand and easy to execute. This method is very much robust in respect of size of the normalized criteria values of the alternatives. It is observed that in comparison to other MCDM methods, like AHP, TOPSIS, ELECTRE VIKOR PROMETHEE, grey relational analysis (GRA), etc., the proposed MCDM method is very simple to understand and easy to implement. It involves the least amount of mathematical calculations, which may be quite useful and helpful to the decision makers. The computation time of the new method would obviously be less. Table 8 depicts the comparative performance of some of the most widely used MCDM methods with respect to their computational time, simplicity, mathematical calculations involved, stability, robustness and type of the information obtained. From this table, it is revealed that in all aspects, the proposed method clearly outperforms the other MCDM methods.

Table 8

Comparative performance of some popular MCDM methods

\begin{tabular}{|c|c|c|c|c|c|c|}
\hline MCDM method & $\begin{array}{l}\text { Computational } \\
\text { time }\end{array}$ & Simplicity & $\begin{array}{l}\text { Mathematical } \\
\text { calculation involved }\end{array}$ & Stability & Robustness & Information type \\
\hline Proposed Method & Very less & Very simple & Minimum & Good & Very high & Quantitative \\
\hline MOORA & Very less & Very simple & Minimum & Good & High & Quantitative \\
\hline AHP & Very high & Very critical & Maximum & Poor & Less & Mixed \\
\hline TOPSIS & Moderate & Moderately critical & Moderate & Medium & Moderate & Quantitative \\
\hline VIKOR & Less & Simple & Moderate & Medium & Moderate & Quantitative \\
\hline ELECTRE & High & Moderately critical & Moderate & Medium & Moderate & Mixed \\
\hline MABAC & Moderate & Moderately critical & Moderate & Medium & Moderate & Quantitative \\
\hline PROMETHEE & High & Moderately critical & Moderate & Medium & Moderate & Mixed \\
\hline
\end{tabular}

The hybrid model consisting of fuzzy AHP and proposed method has been proven to render an effective decision to evaluate two wheelers under requirement perspective of customer. This approach is fit for supporting the decision-makers due to the following benefits. First, fuzzy logic is capable of handling the imprecise, vague and uncertain information from the decision-makers judgments. Second, the impact of the interactions between the attributes is considered in the fuzzy AHP method when determining the weights of the attributes. Lastly, the new method used to obtain the ranking of alternatives. The results show that three highest priorities, most important attributes for women for two wheelers selection are mileage, top speed and kerb weight. Moreover, two another attributes, related to fuel tank capacity and cost are also considered. It is evident from decision matrix that $\mathrm{V} 3$ outperforms in respect to mileage in comparison to other alternatives. Good mileage is one of the indicators of most energy efficient vehicle. This model attain better fuel economy and have lower fuel cost than similar vehicles i.e. reduces the 
running cost of the vehicle. The performance of V2, V4 and V7 is not significant in this criterion. The starting price of V3 is fairly low compare to V1 or V6. Therefore, in all respect V3 is performing best. However, it is also observed in sensitivity plot that this vehicle holds first rank in all the cases.

\section{Conclusion}

It has been observed that the proposed model is simple to use and easy to understand. Also, the computational time requirement is less and the stability of result obtained is high. Finally, a sensitivity analysis has been shown to confirm the robustness of the ranking and further support the decision when selecting the final result. As the proposed Fuzzy AHP-new model is robust, the number of alternatives and evaluation criteria in the decision matrix can be increased to get a more effective decision.

\section{References}

Biswas, T., \& Das, M. (2018a). Selection of hybrid vehicle for green environment using multi-attributive border approximation area comparison method. Management Science Letters, 8(2), 121-130.

Biswas, T. K., \& Das, M. C. (2018b). Selection of commercially available electric vehicle using fuzzy AHP-MABAC. Journal of The Institution of Engineers (India): Series C, 1-7.

Brans, J. P. (1982). L'ingenierie de la decision, l'laboration d'instruments d'aidea la decision. Colloque sur l'Aidea la Decision. Faculte des Sciences de l'Administration, Universite Laval.

Chang, D. Y. (1996). Applications of the extent analysis method on fuzzy AHP. European journal of operational research, 95(3), 649-655.

Charnes, A., Cooper, W. W., \& Rhodes, E. (1978). Measuring the efficiency of decision making units. European journal of operational research, 2(6), 429-444.

Das, M. C., Sarkar, B., \& Ray, S. (2012). A framework to measure relative performance of Indian technical institutions using integrated fuzzy AHP and COPRAS methodology. Socio-Economic Planning Sciences, 46(3), 230-241.

Dağdeviren, M., Yavuz, S., \& Kılınç, N. (2009). Weapon selection using the AHP and TOPSIS methods under fuzzy environment. Expert Systems with Applications, 36(4), 8143-8151.

Haworth, N. (2012). Powered two wheelers in a changing world-Challenges and opportunities. Accident Analysis \& Prevention, 44(1), 12-18. http://doi.or/10.1016/j.aap.2010.10.031

Hsu, T., Sadullah, E., \& Dao, I. (2003). A comparison study on motorcycle traffic development in some Asian countries-case of Taiwan, Malaysia and Vietnam, (October). Retrieved from http://www.easts.info/activities/icra/2001/ICRA. Comparison Study Motorcycle Development.pdf.

Hwang, C. L., \& Yoon, K. (1981). Multiple attribute decision making methods and applications. Springer, Berlin Heidelberg.

Pamučar, D., \& Ćirović, G. (2015). The selection of transport and handling resources in logistics centers using Multi-Attributive Border Approximation area Comparison (MABAC). Expert Systems with Applications, 42(6), 3016-3028.

Rose, G., Thompson, R. G., Amani, B., \& McClure, R. (2012, September). Understanding Ownership and Use of Powered Two Wheelers in Melbourne. In Proc., 35th Australasian Transport Research Forum.

Roy, B. (1968). Classement et choix en présence de points de vue multiples. Revue franiaise d'informatique et de recherche opérationnelle, 2(8), 57-75.

Saaty, T. L. (1980). The analytic hierarchy process (1st ed.). New York: McGraw-Hill.

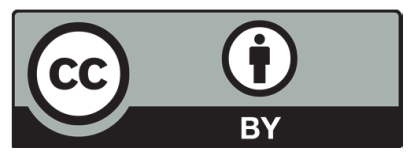

(C) 2019 by the authors; licensee Growing Science, Canada. This is an open access article distributed under the terms and conditions of the Creative Commons Attribution (CCBY) license (http://creativecommons.org/licenses/by/4.0/). 